\title{
Variabilidade genética de 12 loci de microssatélites em galinhas crioulas Canela-Preta
}

[Genetic variability of twelve microsatellite loci in native Canela-Preta chickens]

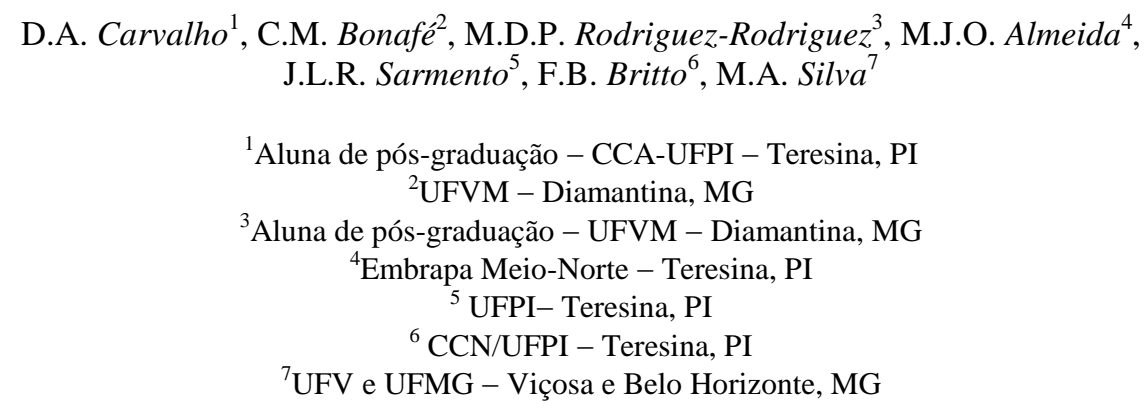

\begin{abstract}
RESUMO
Esta pesquisa foi realizada com o objetivo de se conhecer a variabilidade genética de 12 loci de microssatélites em galinhas crioulas Canela-Preta. Foram coletadas amostras de sangue de 118 galinhas crioulas Canela-Preta, provenientes de três municípios do estado do Piauí (Oeiras, Queimada Nova e Teresina). Após extração do DNA, foram utilizados marcadores para 12 loci de microssatélites: LEI0192, LEI0209, LEI0212, LEI0217, LEI0221, LEI0234, LEI0237, LEI0248, LEI0258, MCW0081, MCW0183 e MCW0213, que foram amplificados pela técnica de reação em cadeia da polimerase (PCR). Foram obtidos 408 alelos (somando os alelos dos 12 loci), com os fragmentos variando entre 50 e 460 pares de bases. O número de alelos variou de 15 (MCW0081) a 52 (LEI0212), com média de 31,5 alelos por locus. A média de heterozigosidade esperada e o conteúdo de informações polimórficas foram, respectivamente, 0,887 e 0,909. Foram observados desvios no equilíbrio de Hardy-Weinberg e valores positivos do índice de fixação com excesso de homozigotos. Os microssatélites utilizados mostraram-se polimórficos e podem ser usados para investigações genéticas em galinhas Canela-Preta. As galinhas dos plantéis avaliados apresentam grande variabilidade gênica, o que as qualifica como importante fonte de recursos genéticos e, consequentemente, faculta a utilização delas em programas de melhoramento genético animal.
\end{abstract}

Palavras-chave: alelos, crioula, Gallus gallus, polimorfismo, Simple Sequence Repeats - SSR

\begin{abstract}
The aim of this study was to analyze the genetic variability of twelve microsatellite loci in native Canela-Preta chickens. Blood samples were collected from 118 chickens of the breed from five properties in three cities (Oeiras, Queimada Nova and Teresina) of Piaui state. After the DNA extraction, markers were used for twelve microsatellite loci: LEI0192, LEI0209, LEIO212, LEIO217, LEIO221, LEI0234, LEIO237, LEI0248, LEIO258, MCW0081, MCW0183, and MCW0213 that were amplified by polymerase chain reaction technique (PCR). The results showed a total of 408 alleles (adding alleles from the 12 loci) with the fragments ranging between 50 and 460 base pairs, the number of alleles ranged from 15 (MCW0081) to 52 (LEIO212) with an average of 31,5 alleles per locus. The average expected heterozygosity and PIC were, respectively, 0.887 and 0.909. Deviations were observed in the Hardy-Weinberg equilibrium and positive values of the fixation index with excess of homozygotes. It is concluded that the used microsatellites are polymorphic and can, therefore, be used for genetic research in Canela-Preta chickens. The birds of the analyzed cores present great genetic variability, which qualifies them as an important source of genetic resources, which could be used for future animal breeding programs.
\end{abstract}

Keywords: allele, crioula, Gallus gallus, Polymorphism, Simple Sequence Repeats - SSR

Recebido em 16 de dezembro de 2016

Aceito em 22 de novembro de 2017

E-mail: deborabie@hotmail.com 


\section{INTRODUÇÃO}

As galinhas domésticas do Brasil foram introduzidas pelos portugueses no período da colonização, por volta do ano 1500. Aqui, essas aves foram criadas soltas em quintais e fazendas o que propiciou cruzamentos aleatórios, passaram por um processo de adaptação e seleção natural, durante décadas e, dessa maneira, surgiram as raças de galinhas crioulas brasileiras. Acredita-se que essas aves são bem adaptadas ao clima, resistentes a parasitas e doenças, sendo consideradas de elevada rusticidade e detentoras de alta variabilidade genética. No entanto, apesar de todas essas qualidades, muitas dessas populações de galinhas crioulas encontram-se em risco de extinção (Fonteque et al., 2014).

Pouco se conhece sobre a variabilidade genética das galinhas crioulas, porém estudos científicos recentes apontam alta variabilidade genética nesse tipo de aves (Fonteque et al., 2014; Kumar et al., 2015; Possamai et al., 2015). O conhecimento da variabilidade genética das galinhas crioulas é fundamental para programas de conservação de recursos genéticos e melhoramento animal, o que viabiliza estabelecer programas de seleção dessas aves. Esta pesquisa foi realizada com o objetivo de avaliar a variabilidade genética de doze loci de microssatélites em galinhas caipiras crioulas Canela-Preta.

\section{MATERIAL E MÉTODOS}

A investigação da variabilidade genética das galinhas caipiras crioulas Canela-Preta foi realizada no Laboratório de Genética Molecular Aplicada do Departamento de Zootecnia da UFVJM, no município de Diamantina-MG. Foram utilizadas amostras de sangue de 118 galinhas crioulas da raça Canela-Preta, de plantéis pertencentes ao Projeto Produtores do Futuro, no Piauí, o qual ocorre em três municípios desse estado: Teresina, localizado a $05^{\circ} 05^{\prime} 20^{\prime \prime} \mathrm{S} 42^{\circ} 48^{\prime}$ 07" O (38 amostras); Oeiras, localizado a $07^{\circ} 01^{\prime} 30^{\prime \prime} \mathrm{S} 42^{\circ} 07^{\prime} 51^{\prime \prime} \mathrm{O}$ (37 amostras); e Queimada Nova, localizado a $08^{\circ} 34^{\prime} 44^{\prime \prime} \mathrm{S} 41^{\circ} 25^{\prime} 08^{\prime \prime} \mathrm{O}$ (43 amostras). Coletou-se sangue da veia ulnar de cada ave, em papel-filtro, o qual foi seco à temperatura ambiente e colocado em envelope devidamente identificado. Este estudo conta com o registro
$\mathrm{N}^{\circ} 04412014$ do Comitê de Ética de Experimentação Animal da Universidade Federal Dos Vales de Jequitinhonha e Mucuri - UFVJM.

Para a extração do DNA genômico, utilizou-se um fragmento de $0,5 \mathrm{~cm}$ do papel-filtro, conforme $\mathrm{o}$ protocolo de extração salina estabelecido por Lopera-Barrero et al. (2008). A quantificação do DNA foi realizada por espectrofotometria, com amplitude de onda 260nm, sendo as amostras diluídas para uma concentração de $10 \mathrm{ng} / \mu \mathrm{L}$. A integridade do DNA foi verificada em eletroforese horizontal, sendo usado um gel de agarose a $1 \%$, a $70 \mathrm{~V}$, por 70 minutos. Posteriormente, capturou-se a imagem no sistema fotográfico UV-312.

A amplificação dos fragmentos de DNA foi realizada pela técnica de reação em cadeia de polimerase (PCR), conforme descrita por McConnell et al. (1999), a partir do DNA total. Foram utilizados 12 loci de microssatélites, desenhados para a espécie Gallus gallus domesticus: LEI0192, LEI0234, LEI0248, MCW0081, MCW0183 (Guidelines..., 2004), LEIO0209, LEI0212, LEI0217, LEI0221, LEI0237, LEI0258 (McConnell et al., 1999) e MCW0213 (Crooijmans et al., 1997).

O DNA foi amplificado em volume de reação de $16 \mu \mathrm{L}$, e cada reação continha 50 ng de DNA, $2,5 \mu \mathrm{L}$ de tampão 10x (100mM Tris-HCl, $\mathrm{pH} 8,3$, $500 \mathrm{mM} \mathrm{KCl}), 1-2,5 \mu \mathrm{L}(20-50 \mathrm{mM})$ de $\mathrm{MgCl} 2$, $2 \mu \mathrm{L}$ da mistura de dNTP $(0,2 \mathrm{mM}$ de dATP,dCTP, dGTP e dTTP), $0,8 \mu \mathrm{M}$ de cada iniciador e 0,5 unidade de Taq DNA polimerase (Ludwig Biotec). A reação em PCR foi realizada por 1 min de desnaturação inicial a $94^{\circ} \mathrm{C}$, em 30 ciclos de $30 \mathrm{~s}$ de desnaturação a $94^{\circ} \mathrm{C}, 30$ s de anelamento a $49-64^{\circ} \mathrm{C}$, dependendo do par de iniciadores (Tab. 1), 50s de extensão a $72^{\circ} \mathrm{C}$ e uma extensão final de $5 \mathrm{~min}$ a $72^{\circ} \mathrm{C}$.

Os produtos da PCR foram visualizados em gel de poliacrilamida desnaturante a $10 \%$ (acrilamida:bisacrilamida - 29:1), ureia $6 \mathrm{~mol} \mathrm{~L}^{-1}$, e foram corados com nitrato de prata, conforme Bassam et al. (1991). Para auxiliar na determinação do tamanho dos fragmentos, foi utilizado um marcador de DNA com fragmentos espaçados de 50 pares de bases (pb) (Invitrogen).

Para cálculo da frequência alélica em cada locus e estimativas das heterozigosidades esperada 
(He) e observada (Ho), foi utilizado o software GenAlEx 6.5 (Peakall e Smouse, 2012). O conteúdo de informações polimórficas (PIC) foi calculado utilizando-se o software Cervus v.3.0.3 (Marshall et al., 1998) (www.fieldgenetics.com). Os testes de probabilidade seguiram o método da cadeia de Markov, adotando-se 1000 steps de memorização, 100 batches e 1000 interações por branches. A correção sequencial de Bonferroni (Rice, 1989) foi adotada para corrigir o efeito de múltiplas comparações, evitando-se a possibilidade de resultados erroneamente significantes (erro tipo I). Para as correlações, adotou-se nível de significância 0,05. Para se verificar a condição do equilíbrio de HardyWeinberg (HWE) em cada locus, foi utilizado o software GENEPOP, v.4.0.10 (Rousset, 2008), e, para avaliar a presença de alelos nulos, foi

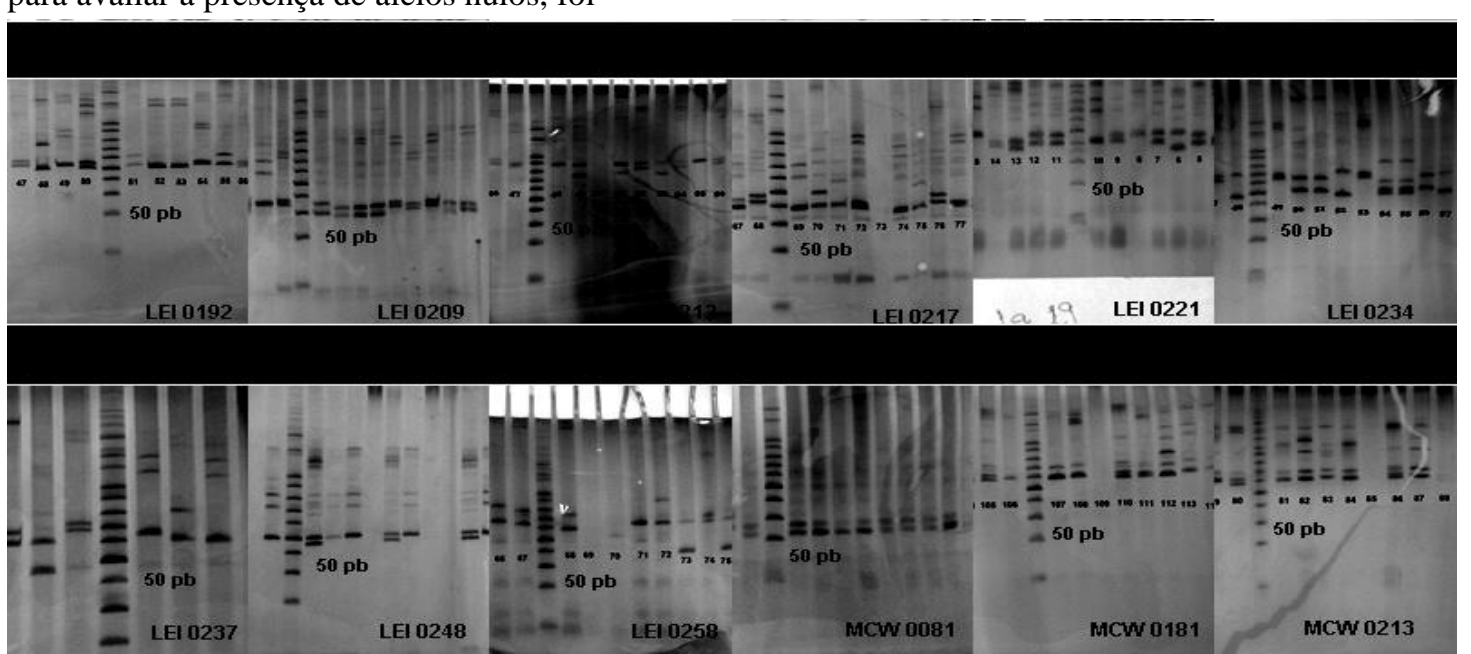

Figura 1. Perfil eletroforético em gel de poliacrilamida mostrando os 12 marcadores microssatélites otimizados para galinhas Canela-Preta $(50 \mathrm{pb}=$ marcador de $50 \mathrm{pb})$.

Nas galinhas crioulas Canela-Preta, obtiveram-se 52 alelos para o locus LEI0258, 45 para LEI0212, 44 para LEI0217, 40 para LEI0234, 37 para LEI0192, 36 para LEI0237, 29 para MCW0183, 21 para LEI0221, 20 para LEI0209, 19 alelos para os loci LEI0248 e MCW0213, e 15 alelos para o locus MCW0081. O elevado polimorfismo das amostras em todos os loci analisados também foi observado por Fonteque et al. (2014), ao analisarem 100 amostras de galinhas caipiras brasileiras de ovos azuis, com o uso de oito desses microssatélites, com 28 alelos para o locus LEI0212, 23 para LEI0217, 22 para LEI0192, 21 para LEI0221, 13 para LEI0248, 12 para LEI0234, oito para MCW0183 e cinco para MCW0081, e por Clementino et al. (2010), com o uso de oito microssatélites em ecotipos de utilizado o software Micro-checker (Van Oosterhout et al., 2004).

\section{RESULTADOS E DISCUSSÃO}

Os 12 loci microssatélites utilizados se mostram eficientes na genotipagem do DNA das 118 galinhas estudadas (Fig. 1). O número de alelos em cada locus variou de 15 (MCW0081) a 52 (LEI0258). A amplificação das amostras gerou um total de 408 alelos, somando-se os alelos de cada locus, com tamanhos de alelos variando entre 50 e 460 pares de bases (Tab. 1). O número de alelos por locus de microssatélite por população de galinhas pode variar muito, podendo ir de um (monomórfico) a vários (polimórfico) (Fonteque et al., 2014). 
número médio de alelos para aves crioulas tem apresentado médias de 3,4 a 19 alelos por loci (Kaya e Yildiz, 2008; Clementino et al., 2010; Fonteque et al., 2014; Kumar et al., 2015), enquanto para linhagens de galinhas comerciais (corte ou postura) tem variado de 1,3 a 8,1 , conforme análises de Crooijmans et al. (1997), Liu et al. (2008) e Dávila et al. (2009).

Tabela 1. Descrição dos loci de microssatélites utilizados para caracterização genética de galinhas Canela-Preta

\begin{tabular}{|c|c|c|c|c|c|c|c|c|}
\hline $\begin{array}{l}\text { Nome } \\
\text { dos Loci }\end{array}$ & $\mathrm{N}^{\circ}$ alelos & $\begin{array}{l}\text { Tamanho } \\
\text { Alelos } \\
\text { Observado(pb) }\end{array}$ & Sequência Forward & Sequência Reverse & $\begin{array}{c}\mathrm{Ta} \\
\left({ }^{\circ} \mathrm{C}\right)\end{array}$ & $\begin{array}{l}\mathrm{MgCl}^{2} \\
(\mathrm{Mm}) \\
(\mu \mathrm{L}) \\
\end{array}$ & $\begin{array}{l}\text { Localização } \\
\text { no Mapa }\end{array}$ & Referência \\
\hline LEI0192 & 37 & $160-355$ & $\begin{array}{c}\text { TGCCAGAGCTTCAG } \\
\text { TCTGT }\end{array}$ & $\begin{array}{c}\text { GTCATTACTGTTATGT } \\
\text { TTATTGC }\end{array}$ & 55 & 1 & Cromossomo 6 & $\begin{array}{l}\text { FAO } \\
(2004)\end{array}$ \\
\hline LEI0209 & 20 & $80-164$ & $\begin{array}{l}\text { AATTTGGTGTCATA } \\
\text { CСTCTCC }\end{array}$ & $\begin{array}{c}\text { GACTTTCCAGTGTCTC } \\
\text { GTTTAG }\end{array}$ & 49 & 1,5 & Cromossomo 1 & $\begin{array}{l}\text { McConnel } \\
\text { let al. } \\
\text { (1999) }\end{array}$ \\
\hline LEI0217 & 44 & $104-376$ & $\begin{array}{c}\text { GATGACTGAGAGA } \\
\text { AATAACTTG }\end{array}$ & $\begin{array}{c}\text { AAATTACTGAGGCACA } \\
\text { GGAG }\end{array}$ & 55 & 1,5 & Cromossomo 1 & $\begin{array}{l}\text { McConnel } \\
\text { let al. } \\
\text { (1999) }\end{array}$ \\
\hline LEI0221 & 21 & $136-376$ & $\begin{array}{c}\text { CCTTTATCCACTCT } \\
\text { TCATGCAC }\end{array}$ & $\begin{array}{c}\text { TGCATAAATTCCATGG } \\
\text { GTAAGC }\end{array}$ & 58 & 1,5 & Cromossomo 1 & $\begin{array}{l}\text { McConnel } \\
\text { 1 et al. } \\
\text { (1999) }\end{array}$ \\
\hline LEI0248 & 19 & $156-264$ & $\begin{array}{c}\text { TTTGAAAGTGACCA } \\
\text { TGATTCTG }\end{array}$ & $\begin{array}{c}\text { AAGCAGTTTCCAAGCT } \\
\text { AAGAAC }\end{array}$ & 61 & 1,5 & Cromossomo 2 & $\begin{array}{l}\text { FAO } \\
(2004)\end{array}$ \\
\hline LEI0258 & 52 & $125-450$ & $\begin{array}{l}\text { CACGCAGCAGAAC } \\
\text { TTGGTAAGG }\end{array}$ & $\begin{array}{c}\text { AGCTGTGCTCAGTCCT } \\
\text { CAGTGC }\end{array}$ & 58 & 1,5 & Cromossomo16 & $\begin{array}{l}\text { McConnel } \\
\text { let al. } \\
\text { (1999) }\end{array}$ \\
\hline MCW081 & 15 & $50-112$ & $\begin{array}{l}\text { GTTGCTGAGAGCCT } \\
\text { GGTGCAG }\end{array}$ & $\begin{array}{c}\text { CCTGTATGTGGAATTA } \\
\text { CTTCTC }\end{array}$ & 60 & 2 & Cromossomo 5 & $\begin{array}{l}\text { FAO } \\
(2004\end{array}$ \\
\hline MCW083 & 29 & $220-420$ & $\begin{array}{c}\text { ATCCCAGTGTCGAG } \\
\text { TATCCGA }\end{array}$ & $\begin{array}{c}\text { TGAGATTTACTGGAGC } \\
\text { CTGCC }\end{array}$ & 64 & 1 & Cromossomo 7 & $\begin{array}{l}\text { FAO } \\
(2004\end{array}$ \\
\hline MCW013 & 19 & $150-352$ & $\begin{array}{l}\text { CTGTTCACTTTAAG } \\
\text { GACATGG }\end{array}$ & $\begin{array}{l}\text { GACAAGTCAACAACTT } \\
\text { GCCAG }\end{array}$ & 55 & 1,5 & Cromossomo13 & $\begin{array}{c}\text { Crooijman } \\
\text { s et al. } \\
\text { (1997) }\end{array}$ \\
\hline
\end{tabular}

X - Cromossomo não informado; *Numero de alelos encontrados na pesquisa; Ta - Temperatura anelamento.

Pesquisas têm sido feitas no Brasil e no exterior utilizando microssatélites para caracterizar geneticamente galinhas crioulas. No Brasil, Clementino et al. (2010) encontraram variação de três a 18 alelos por locus e Fonteque et al. (2014) obtiveram variação de dois a 28 alelos por locus. No entanto, corroborando os resultados desta pesquisa, na China, Qu et al. (2006) e, na Índia, Kumar et al. (2015) obtiveram variação de seis a 51 e de cinco a 43 alelos por locus, respectivamente.

As aves comerciais sofrem forte pressão de seleção e apresentam, em geral, menor número de alelos por loci que as aves crioulas (Blackburn, 2006). Nas populações aqui analisadas, os valores foram ainda superiores aos obtidos em pesquisas com galinhas crioulas no Brasil, o que demonstra elevada variabilidade genética das galinhas caipiras brasileiras CanelaPreta e as qualifica como fonte de variabilidade genética, que devem ser conservadas visando ao estabelecimento de programas de conservação e melhoramento genético dessa raça.

O valor médio do conteúdo de informações polimórficas (PIC) foi de 0,909, variando de 0,745 (MCWOO81) a 0,967 (LEI0258), resultado que indica elevada variabilidade e polimorfismo nas populações avaliadas, além de sugerir que mais informações genéticas podem ser fornecidas por esses loci de marcadores "Simple Sequence Repeats" (SSR), considerando-se que marcadores que apresentam valores de PIC acima de 0,5 são apontados como muito informativos (Costa e Lorenzo, 2009) (Tab.2). 
Variabilidade genética...

Tabela 2. Polimorfismo de 12 loci de microssatélites em 118 amostras de DNA de galinhas Canela-Preta

\begin{tabular}{|c|c|c|c|c|c|c|c|}
\hline LOCUS & $\mathrm{N}_{\mathrm{A}}{ }^{1}$ & $\mathrm{H}_{\mathrm{O}}{ }^{2}$ & $\mathrm{H}_{\mathrm{E}}^{3}$ & $\mathrm{~T}(\mathrm{~PB})^{4}$ & $\mathrm{PIC}^{5}$ & $\mathrm{AN}^{6}$ & Valor de $\mathrm{P}^{7}$ \\
\hline LEI0192 & 21,333 & 0,650 & 0,916 & $160-355$ & 0,941 & 0,1827 & 0,0124 \\
\hline LEI0209 & 14,000 & 0,695 & 0,889 & $80-164$ & 0,902 & 0,1412 & 0,0000 \\
\hline LEI0212 & 27,66 & 0,550 & 0,936 & $280-460$ & 0,957 & 0,2714 & 0,0000 \\
\hline LEI0217 & 23,333 & 0,692 & 0,918 & $104-376$ & 0,936 & 0,1567 & 0,0000 \\
\hline LEI0221 & 14,333 & 0,550 & 0,880 & $136-296$ & 0,892 & 0,2403 & 0,0000 \\
\hline LEI0234 & 23,667 & 0,567 & 0,925 & $148-420$ & 0,952 & 0,2651 & 0,0000 \\
\hline LEI0237 & 24,333 & 0,720 & 0,925 & $176-448$ & 0,942 & 0,1369 & 0,0000 \\
\hline LEI0248 & 12,000 & 0,243 & 0,807 & $156-264$ & 0,854 & 0,5582 & 0,0000 \\
\hline LEI0258 & 30,000 & 0,721 & 0,941 & $125-450$ & 0,967 & 0,1508 & 0,0000 \\
\hline MCW0081 & 7,667 & 0,939 & 0,721 & $50-112$ & 0,745 & $-0,1221$ & 0,0000 \\
\hline MCW0183 & 20,667 & 0,829 & 0,928 & $220-420$ & 0,940 & 0,0635 & 0,0000 \\
\hline MCW0213 & 12,333 & 0,926 & 0,860 & $150-352$ & 0,886 & $-0,0202$ & 0,0000 \\
\hline MÉDIA & 19,278 & 0,674 & 0,887 & - & 0,909 & - & - \\
\hline
\end{tabular}

${ }^{1}$ Frequência de alelos por locus; ${ }^{2}$ heterozigosidade observada; ${ }^{3}$ heterozigosidade esperada; ${ }^{4}$ tamanho de alelos em pares de base; ${ }^{5}$ conteúdo de informação polimórfica; ${ }^{6}$ alelos nulos; ${ }^{7}$ locus em desequilíbrio $(\mathrm{P}<0,05)$.

As médias de heterozigosidade esperada $(\mathrm{He})$ e observada (Ho) foram 0,887 e 0,674 , respectivamente, o que reflete adequação dos marcadores SSR para medir a variação genética das galinhas Canela-Preta (Tab. 2).

Heterozigosidade de um marcador é a probabilidade de um indivíduo ser heterozigoto no locus marcador e depende do número de alelos e de sua frequência na população, podendo ser considerada uma medida de diversidade genética. Para galinhas crioulas, os valores ficam em torno de 0,56 a 0,86 para $\mathrm{He}$, e entre 0,38 a 0,63 para Ho (Kaya e Yildiz, 2008; Fonteque et al., 2014). Os dados desta pesquisa são compatíveis com os valores encontrados em aves crioulas. Para aves comerciais (linhagens), a $\mathrm{He}$ média tem variado entre 0,00 (para linhagens altamente endogâmicas) e 0,74 , e a Ho média entre 0,00 e 0,67 (Dávila et al., 2009; Tadano et al., 2009).

Marcador molecular é considerado polimorficamente informativo, sendo eficiente para medir a variação genética quando sua heterozigosidade é maior que $70 \%$. A Ho é considerada elevada quando apresenta média maior que 0,7 , e reduzida quando menor que 0,5 . Quanto à He, médias superiores a 0,5 indicam elevada diversidade genética dos marcadores (Menezes et al., 2006).

A He média por loci variou de 0,721 a 0,941 , e a Ho média de 0,243 a 0,939. A maior $\mathrm{He}$ foi obtida para o locus LEI0258, e a maior Ho para o locus MCW0081, sendo as menores He e Ho observadas para os loci MCW0081e LEI0248, respectivamente. A Ho foi menor que a He para todos os loci avaliados, exceto para os loci MCW0081 e MCW0213. Os marcadores LEI0237, LEI0258, MCW0081, MCW0183 e MCW0213 apresentaram elevado grau de Ho, com média superior a 0,7. Os marcadores LEI0192, LEI0209, LEI0212, LEI0217, LEI0221, LEI0234 apresentaram Ho média intermediária, entre 0,5 e 0,7. Apenas o marcador LEI0248 apresentou baixa Ho, com média menor que 0,5 .

Verificou-se elevada diversidade genética dos marcadores SSR analisados, tendo 92\% dos marcadores apresentado Ho superior a 0,5, enquanto todos os loci apresentaram He superior a 0,5 .

Os 12 loci estudados apresentaram desvios do equilíbrio de Hardy-Weinberg (EHW) para as populações em estudo (Tab. 2). Segundo Fonteque et al. (2014), os desvios de EHW podem ser devido a diversos fatores, como acasalamentos direcionados, subdivisões dentro das populações, antepassados comuns, seleção natural ou artificial, migração ou fluxo de genes a partir de população externa, além da presença de alelos nulos. Uma característica em comum das galinhas caipiras é o sistema de criação extensivo, em que pequenas populações são criadas livres a campo. 
Essas pequenas populações geralmente apresentam reduzido número de indivíduos com alto grau de parentesco e pouca utilização de reprodutores, que geralmente são selecionados pela beleza ou pelo porte físico, o que predispõe a altas taxas de endogamia. As galinhas brasileiras Canela-Preta apresentam esse sistema de criação comum das aves caipiras, $\log o$ são populações pequenas e são submetidas tanto à seleção natural sobre as fêmeas, como artificial sobre os machos, que correspondem a $50 \%$ da genética do plantel. Observou-se a presença de alelos nulos nas populações estudas (Tab. 2). A ocorrência de desvios quanto ao equilíbrio de Hardy-Weinberg também foi verificada em diversos trabalhos com aves (Dávila et al., 2009; Fonteque et al., 2014; Kumar et al., 2015).

As médias dos alelos e de heterozigosidades sugerem elevada variabilidade genética em galinhas crioulas Canela-Preta, o que torna importante a conservação desses animais como fonte de recursos genéticos, os quais poderão ser utilizados, no futuro, em programas de melhoramento genético de galinhas.

\section{CONCLUSÃO}

As galinhas crioulas Canela-Preta apresentaram elevada variabilidade genética para os loci analisados, o que sugere a conservação desse material genético, que deve ser mais estudado. Todos os loci de microssatélites utilizados nas análises foram significativamente polimórficos, o que demonstra alta variação entre as amostras. Portanto, eles podem ser utilizados em análises de variabilidade genética populacional e caracterização das galinhas Canela-Preta.

\section{AGRADECIMENTOS}

Os autores agradecem ao suporte financeiro da Fapemig, à Capes, à UFVJM, ao Projeto "Produtores do Futuro" e à Embrapa MeioNorte.

\section{REFERENCIAS}

BASSAM, B.J.; CAETANO, A.G.; GRESSHOFF, P.M. Fast and sensitive silver staining of DNA in polyacrylamide gels. Anal. Biochem., v.196, p.80-83, 1991.
BLACKBURN, H.D. The National Animal Germplasm Program: challenges and opportunities for poultry genetic resources. Poult. Sci., v.85, p.210-215, 2006.

CLEMENTINO, C.S.; BARBOSA, F.J.V.; CARVALHO, A.M.F. et al. Microsatellite DNA loci for population studies in Brazilian chicken ecotypes. Int. J. Poult. Sci., v.9, p.1100-1106, 2010.

COSTA, J.; LORENZO, M. Biology, diversity and strategies for the monitoring and control of triatomines - Chagas disease vectors. Mem. Inst. Oswaldo Cruz, v.104, Suppl.1, p.46-51, 2009.

CROOIJMANS, R.P.M.A.; DIJKHOF, R.J.M.; VAN DER POEL, J.J.; GROENEN, M.A.M. New microsatellite markers in chicken optimized for automated fluorescent genotyping. Anim. Genet., v.28, p.427-437, 1997.

DÁVILA， S.G.; GIL, M.G.; RESINOTALAVÁN, P.; CAMPO, J.L. Evaluation of diversity between different Spanish chicken breeds, a tester line, and a White Leghorn population based on microsatellite markers. Poult. Sci., v.88, p.2518-2525, 2009.

FONTEQUE, G.V.; BATTILANA, J.; PALUDO, E.; LIMA-ROSA, C.A.V. Genetic polymorphism of fifteen microsatellite loci in Brazilian (blue-egg Caipira) chickens. Pesqui. Vet. Bras., v.34, p.98-102, 2014.

GUIDELINES for development of national management of farm animal genetic resources plans: Measurement of Domestic Animal Genetic Diversity (MoDAD): recommended microsatellite markers. Rome, Italy: FAO, 2004. $58 \mathrm{p}$.

KAYA, M.; YILDIZ, M.A. Genetic diversity among Turkish native chickens, Denizli and Gerze, estimated by microsatellite markers. Biochem. Genet., v.46, p.480-491, 2008.

KUMAR, V.; SHUKLA, S.K.; MATHEW, J.; SHARMA, D. Genetic diversity and population structure analysis between Indian red jungle fowl and domestic chicken using microsatellite markers. Anim. Biotechnol., v.26, p.201-210, 2015.

LIU, G.Q.; JIANG, X.P.; WANG, J.Y. et al. Analysis of genetic diversity of Yangzhou Chicken by microsatellite markers. Int. J. Poult. Sci., v.7, p.1237-1241, 2008. 
LOPERA-BARRERO, N.M.; POVH, J.A.; RIBEIRO, R.P. et al. Comparación de protocolos de extracción de ADN con muestras de aleta y larva de peces: extracción modificada con cloruro de sodio. Cienc. Invest. Agrar., v.35, p.77-86, 2008.

MARSHALL, T.C.; SLATE, J.; KRUUK, L.E.; PEMBERTON, J.M. Statistical confidence for likelihood-based paternity inference in natural populations. Mol. Ecol., v.7, p.639-655, 1998.

McCONNELL, S.K.J.; DAWSON, D.A.; WARDLE, A.; BURKE, T. The isolation and mapping of 19 tetranucleotide microsatellite markers in the chicken. Anim. Genet., v.30, p.183-189, 1999.

MENEZES, M.P.C.; MARTINEZ, A.M.; RIBEIRO, M.N. et al. Caracterização genética de raças caprinas nativas brasileiras utilizando-se 27 marcadores microssatélites. Rev. Bras. Zootec., v.35, p.1336-1341, 2006.

PEAKALL, R.; SMOUSE, P.E. GenAIEx 6.5: genetic analysis in Excel. Population genetic software for teaching and research-an update. Bioinformatics, v.28, p.2537-2539, 2012.
POSSAMAI, M.H.P.; BATTILANA, J.; PALUDO, E. et al. Genotypic characterization of ten microsatellite loci in two Brazilian free range

(Caipira) chicken lines. Ciênc. Rural, v.45, p.877-883, 2015.

QU, L.; LI, X.; XU, G. et al. Evaluation of genetic diversity in Chinese indigenous chicken breeds using microsatellite markers. Sci. China. S. C, Life Sci., v.49, p.332-341, 2006.

RICE, W.R. Analyzing tabelas of statistical tests. Evolution, v.43, p.223-225, 1989.

ROUSSET, F. GENEPOP'007: a complete reimplementation of the GENEPOP software for Windows and Linux. Mol. Ecol., v.8, p.103-106, 2008.

TADANO, R.; NISHIBORI, M.; TSUDZUKI, M. Genetic structure and differentiation of the Japanese extremely long-tailed chicken breed (Onagadori), associated with plumage colour variation: suggestions for its management and conservation. Anim. Genet., v.40, p.989-992, 2009.

VAN OOSTERHOUT, C.; HUTCHINSON, W.F.; WILLS, D.P.M.; SHIPLEY, P. Micro-Checker: software for identifying and correcting genotyping errors in microsatellite data. Mol. Ecol., v.4, p.535-538, 2004. 